\title{
Catalyst Initiation in the Oscillatory Carbonylation Reaction
}

\author{
Katarina Novakovic and Julie Parker \\ School of Chemical Engineering and Advanced Materials, Newcastle University, Newcastle upon Tyne NE1 7RU, UK \\ Correspondence should be addressed to Katarina Novakovic, katarina.novakovic@ncl.ac.uk
}

Received 16 March 2011; Revised 21 April 2011; Accepted 26 April 2011

Academic Editor: D. Yu. Murzin

Copyright $\odot 2011$ K. Novakovic and J. Parker. This is an open access article distributed under the Creative Commons Attribution License, which permits unrestricted use, distribution, and reproduction in any medium, provided the original work is properly cited.

\begin{abstract}
Palladium(II) iodide is used as a catalyst in the phenylacetylene oxidative carbonylation reaction that has demonstrated oscillatory behaviour in both $\mathrm{pH}$ and heat of reaction. In an attempt to extract the reaction network responsible for the oscillatory nature of this reaction, the system was divided into smaller parts and they were studied. This paper focuses on understanding the reaction network responsible for the initial reactions of palladium(II) iodide within this oscillatory reaction. The species researched include methanol, palladium(II) iodide, potassium iodide, and carbon monoxide. Several chemical reactions were considered and applied in a modelling study. The study revealed the significant role played by traces of water contained in the standard HPLC grade methanol used.
\end{abstract}

\section{Introduction}

The palladium-catalysed phenylacetylene oxidative carbonylation (PCPOC) reaction stands out in a number of respects. It provides a novel $\mathrm{pH}$ oscillator operating in a stirred batch reactor [1-8]. Furthermore, when operating the PCPOC system in an oscillatory regime high levels of product selectivity are reported compared to operating in a nonoscillatory mode [6]. The ability to achieve selective product formation in this way is a new and notable result in terms of reaction engineering that, once understood, may be imposed on and exploited in industrially significant reactions. Moreover, the PCPOC reaction represents the first example of complex molecules synthesised from relatively simple reagents proceeding in a catalytic system in an oscillatory mode. Scientifically this is significant as all other oscillating processes, including those driven by heterogeneous catalysis, involve the oxidation, hydrogenation, or destruction of complex molecules [3]. In addition to oscillations in $\mathrm{pH}$, the PCPOC reaction has the capacity to produce significant oscillatory pulses of heat (i.e., $600 \mathrm{~J} /$ oscillation) over long periods of time (i.e., days) that may be regulated by the reaction conditions $[5,6,8]$. For that reason, the importance of the PCPOC reaction for $\mathrm{pH}$ and temperature-responsive "smart materials" and their future applications may be foreseen, for example, in drug delivery [9].
The aforementioned results imply the need for a fundamental understanding of the PCPOC reaction in order to make use of the observed phenomena and apply the knowledge gained to other systems. The key to achieving this is in obtaining a reaction network (i.e., rate determining reactions in a chemical mechanism) responsible for the oscillatory nature of the $\mathrm{PCPOC}$ reaction. The $\mathrm{PCPOC}$ reaction system on initiation consists of seven species: $\mathrm{CH}_{3} \mathrm{OH}, \mathrm{PdI}_{2}$, $\mathrm{KI}, \mathrm{NaOAc}, \mathrm{CO}$, Air, and $\mathrm{C}_{8} \mathrm{H}_{6}$. Conducting mechanistic modelling studies is difficult due to the large number of species. In this work, a strategy that reduces complexity is applied. The overall system is simplified to a series of subsystems consisting of as little as two species. The role of each species in the subsystem and their interaction with other species is investigated experimentally and data obtained are employed in modelling studies. The experimental studies are performed in standard laboratory glassware with a magnetic stirrer, using HEL MicroNOTE for on-line data logging. BatchCAD software is used for kinetic fitting, modelling and simulation studies. An all-aqueous $\mathrm{pH}$-meter setup consisting of aqueous $\mathrm{pH}$ electrode filling solution and aqueous calibration buffers is used in all experiments. The $\mathrm{pH}$ values measured with this procedure are often called apparent $\mathrm{pH}$ values $\left(\mathrm{pH}_{\mathrm{app}}\right)$ [10]. The $\mathrm{pH}$ measurements are employed in the modelling study as hydrogen ion concentration. When water is used as the solvent, hydrogen 
ion concentration is calculated from the recorded $\mathrm{pH}$ as $10^{-\mathrm{pH}}$. However, when methanol is used as the solvent the recorded $\mathrm{pH}$ values are adjusted by adding $2.3 \mathrm{pH}$ units to the apparent $\mathrm{pH}$ values [11]. The adjusted $\mathrm{pH}$ value $\left(\mathrm{pH}_{\mathrm{app}}+\right.$ 2.3 ) is then used to calculate hydrogen ion concentration.

This paper focuses on understanding the reaction network responsible for the initial reactions of the catalyst within the PCPOC reaction. The species researched include $\mathrm{CH}_{3} \mathrm{OH}, \mathrm{PdI}_{2}, \mathrm{KI}$, and $\mathrm{CO}$. This subsystem is not only important to understand the overall oscillatory behaviour recorded in the PCPOC system but also to further understand palladium-catalysed reductive carbonylation reactions of alkynes that may lead to the formation of a wide range of products [12, 13]. All chemicals used in this study were purchased from Sigma-Aldrich and employed without further manipulation unless otherwise stated.

\section{Experimental Study}

2.1. $\mathrm{PdI}_{2}, \mathrm{KI}$, and CO Solubility in Methanol. The solubility of $\mathrm{PdI}_{2}$ in methanol was investigated initially. Upon $\mathrm{PdI}_{2}$ addition, a small drop in $\mathrm{pH}_{\text {app }}$ occurred (from 7.6 to 7.5). Still the bulk of the added solid $\mathrm{PdI}_{2}$ was visible in the beaker $\left(150 \mathrm{~mL}\right.$ methanol, $8 \mathrm{mg} \mathrm{PdI}_{2}$ at room temperature $21.4^{\circ} \mathrm{C}$ ). The temperature of the beaker contents was gradually increased attempting to increase $\mathrm{PdI}_{2}$ solubility. The increase in temperature did not significantly affect $\mathrm{pH}_{\text {app }}$ and the bulk of the added solid $\mathrm{PdI}_{2}$ remained visible.

The solubility of KI in methanol was looked at next. The addition of KI to the PCPOC reaction system aids the solubility of $\mathrm{PdI}_{2}$ in methanol. The solubility of $\mathrm{KI}$ in methanol at room temperature $\left(21.4^{\circ} \mathrm{C}\right)$ was determined experimentally by adding $\mathrm{KI}$ to $50 \mathrm{~mL}$ of methanol until precipitation occurred. The maximum concentration of KI at $21.4^{\circ} \mathrm{C}$ was measured to be $7.51 \cdot 10^{-1} \mathrm{~mol} / \mathrm{dm}^{3}$.

$\mathrm{PdI}_{2}$ solubility in concentrated KI solution in methanol was then investigated experimentally. Initial trials suggested that the rate of dissolution of $\mathrm{PdI}_{2}$ plays an important role. Experiments were performed at room temperature $\left(21^{\circ} \mathrm{C}\right)$. In the first one, $25 \mathrm{~mL}$ of methanol, $2 \mathrm{~g}$ of $\mathrm{KI}$, and $50 \mathrm{mg}$ of $\mathrm{PdI}_{2}$ were placed into a vial and stirred for 6 days using a magnetic stirrer. After filtration over a $0.2 \mu \mathrm{m}$ millipore membrane filter, $46 \mathrm{mg}$ of $\mathrm{PdI}_{2}$ remained in the solution. This corresponds to a $\mathrm{PdI}_{2}$ solubility of $5.11 \cdot 10^{-3} \mathrm{~mol} / \mathrm{dm}^{3}$ in the presence of $4.80 \cdot 10^{-1} \mathrm{~mol} / \mathrm{dm}^{3}$ of $\mathrm{KI}$ in methanol at $21^{\circ} \mathrm{C}$. This concentration of $\mathrm{KI}$ in methanol was chosen as this is the concentration used in the oscillatory experiments previously reported [8]. A second experiment using $25 \mathrm{~mL}$ of methanol, $2 \mathrm{~g}$ of $\mathrm{KI}$, and $500 \mathrm{mg}$ of $\mathrm{PdI}_{2}$ was stirred for 12 weeks. After filtration $433 \mathrm{mg}$ of $\mathrm{PdI}_{2}$ remained in the solution corresponding to $4.81 \cdot 10^{-2} \mathrm{~mol} / \mathrm{dm}^{3}$ in $4.80 \cdot 10^{-1} \mathrm{~mol} / \mathrm{dm}^{3}$ of $\mathrm{KI}$ in methanol at room temperature (varying between 20 and $21.5^{\circ} \mathrm{C}$ ). These experiments demonstrate that the solubility of $\mathrm{PdI}_{2}$ in methanol in the presence of KI is governed by the rate of solubility. It takes weeks for the maximum solubility to be achieved.

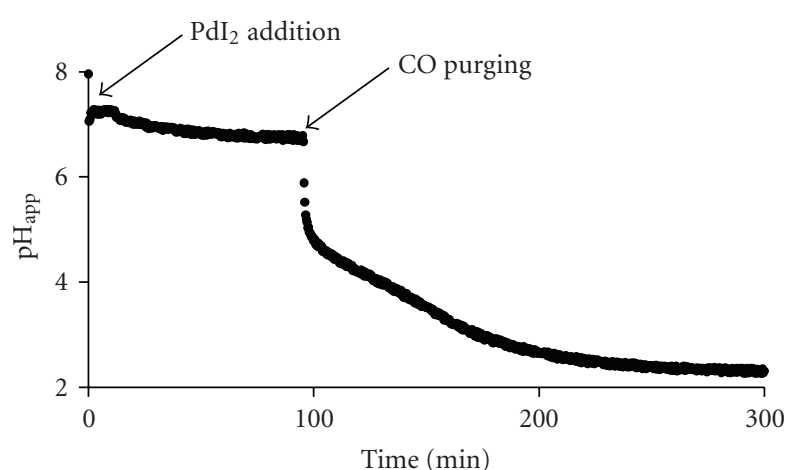

Figure 1: $[\mathrm{KI}]=4.8 \cdot 10^{-1} \mathrm{~mol} / \mathrm{dm}^{3} ;\left[\mathrm{PdI}_{2}\right]_{\text {if all dissolved }}=2.66$. $10^{-3} \mathrm{~mol} / \mathrm{dm}^{3} ; \mathrm{CO}_{\text {flow }}=6 \mathrm{~mL} / \mathrm{min} ; 25 \mathrm{~mL}$ of methanol.

The solubility of carbon monoxide in methanol is an important variable as it can be a limiting factor on reaction rates. The solubility of $\mathrm{CO}$ in methanol is estimated to be $8.26 \cdot 10^{-3} \mathrm{~mol} / \mathrm{dm}^{3}$ at $20^{\circ} \mathrm{C}$ using two software packages, BatchCad and DynoChem. The rate of carbon monoxide solubility is reported to be fast [14].

2.2. $\mathrm{PdI}_{2}, \mathrm{KI}, \mathrm{CO}$, and Methanol Reaction Network Experimental Investigation. All experiments were conducted at room temperature (approximately $21^{\circ} \mathrm{C}$ ) with the aim of analysing $\mathrm{pH}$ behaviour. Carbon monoxide was supplied via a diptube, and $\mathrm{pH}$ and temperature were monitored using HEL MicroNOTE.

The first experiment focused on the understanding of the reaction network involving the interaction of $\mathrm{PdI}_{2}$ with $\mathrm{CO}$. The concentrations of $\mathrm{PdI}_{2}$ and $\mathrm{KI}$ were kept the same as in the oscillatory experiments previously reported $[6,8]$ while the total volume of the run as well as CO flow was scaled down. The experiment was performed as follows: potassium iodide $(2 \mathrm{~g})$ was dissolved in $25 \mathrm{~mL}$ of methanol then $24 \mathrm{mg}$ of palladium(II) iodide was added. Eighty-three minutes after $\mathrm{PdI}_{2}$ addition, purging with carbon monoxide $(6 \mathrm{~mL} / \mathrm{min})$ commenced. The colour of the solution was dark red-brown and no precipitate was observed. The recorded $\mathrm{pH}_{\text {app }}$ is presented in Figure 1.

As shown in Figure 1, an immediate sharp $\mathrm{pH}_{\text {app }}$ drop from 6.8 to 5 over 2.5 minutes occurred when purging with $\mathrm{CO}$ commenced. After this initial drop $\mathrm{pH}_{\text {app }}$ continued to fall more slowly from 5 to 2.9 over approximately 75 minutes. This was followed by an even slower drop in $\mathrm{pH}_{\text {app }}$ from 2.9 to 2.3 over approximately 2 hours until $\mathrm{pH}_{\text {app }}$ settled at a value of 2.3.

The drop in $\mathrm{pH}$ upon $\mathrm{CO}$ addition suggests a chemical reaction that produces hydrogen ions. In this experimental system two sources of hydrogen ions are present: methanol and water (as the experiment is not conducted under dry conditions). To investigate the roles of methanol and water experiments were conducted in the following solvents: water, dry methanol, standard HPLC grade methanol and dry acetone.

2.3. Water as Solvent. In this experiment, water was used as solvent instead of methanol. KI $(2 \mathrm{~g})$ was dissolved in 


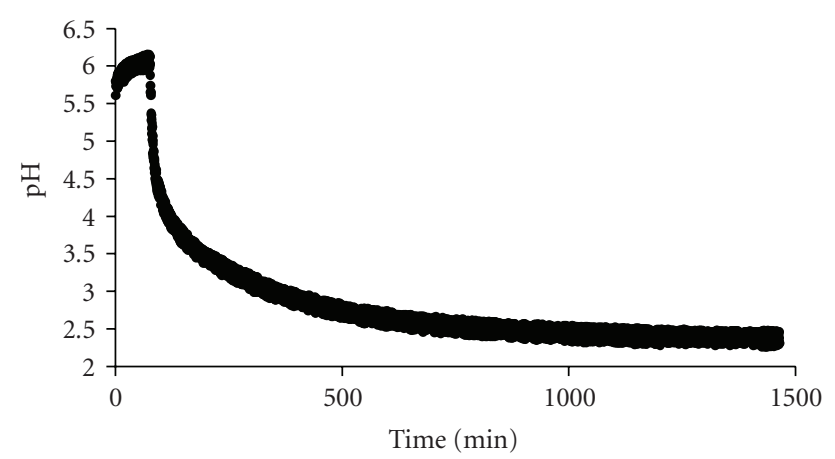

Figure 2: $[\mathrm{KI}]=4.8 \cdot 10^{-1} \mathrm{~mol} / \mathrm{dm}^{3} ;\left[\mathrm{PdI}_{2}\right]_{\text {if all dissolved }}=2.66$. $10^{-3} \mathrm{~mol} / \mathrm{dm}^{3} ; \mathrm{CO}_{\text {flow }}=6 \mathrm{~mL} / \mathrm{min} ; 25 \mathrm{~mL}$ of water.

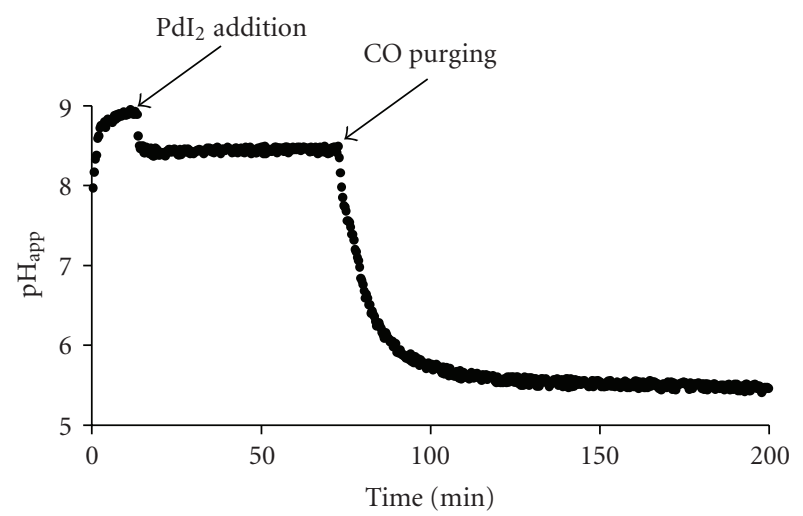

FIGURE 3: $[\mathrm{KI}]=4.8 \cdot 10^{-1} \mathrm{~mol} / \mathrm{dm}^{3} ;\left[\mathrm{PdI}_{2}\right]_{\text {if all dissolved }}=2.66$. $10^{-3} \mathrm{~mol} / \mathrm{dm}^{3} ; \mathrm{CO}_{\text {flow }}=6 \mathrm{~mL} / \mathrm{min} ; 25 \mathrm{~mL}$ of dry methanol.

$25 \mathrm{~mL}$ of deionised water, and then $24 \mathrm{mg}$ of $\mathrm{PdI}_{2}$ was added. Approximately $1 \mathrm{~h}$ after the addition of palladium(II) iodide, purging with carbon monoxide $(6 \mathrm{~mL} / \mathrm{min})$ began. The colour of the solution was initially brown, then over the course of the experiment it became colourless and a black precipitate was observed. The $\mathrm{pH}$ results are presented in Figure 2.

2.4. Dry Methanol as Solvent. This experiment used dry methanol as solvent instead of standard grade methanol. Water was removed from the methanol using molecular sieves (pore size $3 \AA$ and absorption $\geq 15 \%$ ). A stock solution of $\mathrm{KI}$ in methanol was made $(8 \mathrm{~g}$ of $\mathrm{KI}$ and $100 \mathrm{~mL}$ of $\mathrm{CH}_{3} \mathrm{OH}$ ), molecular sieves were added (4.672 g), and the mixture was stirred for approximately $20 \mathrm{~h}$. The experiment was performed as follows: $1 \mathrm{~g}$ of fresh molecular sieves was placed into an empty vial followed by $25 \mathrm{~mL}$ of the previously prepared stock solution and $24 \mathrm{mg}$ of $\mathrm{PdI}_{2}$. Carbon monoxide addition $(6 \mathrm{~mL} / \mathrm{min})$ commenced approximately $1 \mathrm{~h}$ after $\mathrm{PdI}_{2}$ was added. The colour of the solution was dark redbrown, and no precipitate was observed. The $\mathrm{pH}_{\text {app }}$ results are presented in Figure 3.

2.5. Standard Grade "Wet" Methanol as Solvent. In this experiment, potassium iodide $(8 \mathrm{~g})$ was dissolved in $100 \mathrm{~mL}$ of methanol. $\mathrm{PdI}_{2}(96 \mathrm{mg})$ was added to this solution and

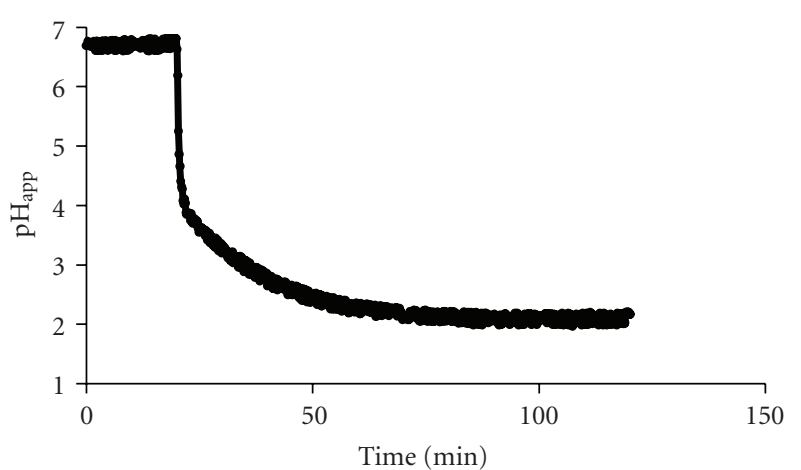

Figure 4: $[\mathrm{KI}]=4.8 \cdot 10^{-1} \mathrm{~mol} / \mathrm{dm}^{3} ;\left[\mathrm{PdI}_{2}\right]=2.22 \cdot 10^{-3} \mathrm{~mol} / \mathrm{dm}^{3}$; $\mathrm{CO}_{\text {flow }}=6 \mathrm{~mL} / \mathrm{min} ; 25 \mathrm{~mL}$ of "wet" methanol.

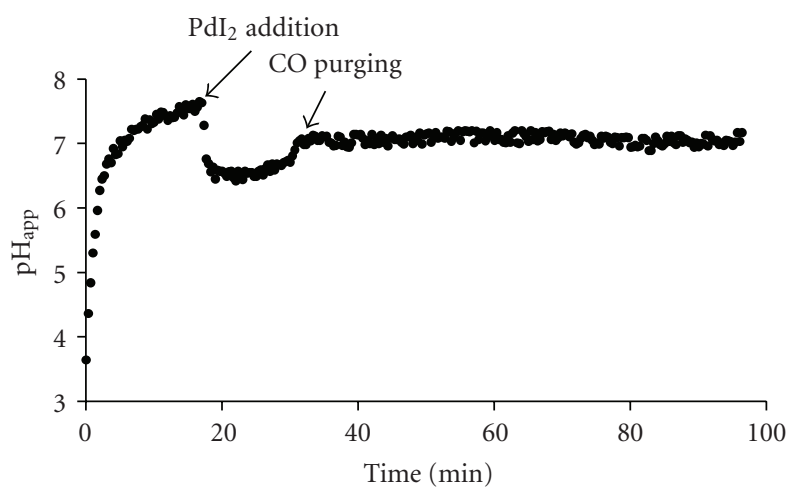

FIGURE 5: $[\mathrm{KI}]_{\max }=6.4 \cdot 10^{-1} \mathrm{~mol} / \mathrm{dm}^{3} ;\left[\mathrm{PdI}_{2}\right]_{\text {if all dissolved }}=2.66$. $10^{-3} \mathrm{~mol} / \mathrm{dm}^{3} ; \mathrm{CO}_{\text {flow }}=6 \mathrm{~mL} / \mathrm{min} ; 25 \mathrm{~mL}$ of dry acetone.

stirred for 24 hours. The mixture was then filtered over a $0.2 \mu \mathrm{m}$ millipore membrane filter. After filtration, $80 \mathrm{mg}$ of $\mathrm{PdI}_{2}$ remained in the solution and $25 \mathrm{~mL}$ of this filtered solution was placed in a vial. The mixture was stirred at room temperature $\left(20^{\circ} \mathrm{C}\right)$ for 20 minutes before $\mathrm{CO}$ addition started $(6 \mathrm{~mL} / \mathrm{min})$. The $\mathrm{pH}_{\text {app }}$ recorded in this run is presented in Figure 4. Throughout the experiment no black precipitate was visible.

2.6. Dry Acetone as Solvent. This experiment used acetone which had been previously dried using molecular sieves. A stock solution of $75 \mathrm{~mL}$ of acetone, $8 \mathrm{~g}$ of potassium iodide, and $4 \mathrm{~g}$ of molecular sieves was prepared. It was noticed that the potassium iodide did not fully dissolve. As before $25 \mathrm{~mL}$ of this mixture was placed into a vial along with $24 \mathrm{mg}$ of palladium(II) iodide. The mixture was stirred for approximately $15 \mathrm{~min}$ before adding carbon monoxide $(6 \mathrm{~mL} / \mathrm{min})$. The $\mathrm{pH}_{\text {app }}$ results are presented in Figure 5.

From these five experiments (Figures 1 to 5 ), the following observations were made.

(i) The drop in $\mathrm{pH}$ upon carbon monoxide addition occurs only in the system with a component that may act as a proton donor. It exists in methanol, dry methanol, and water solutions but does not take place in dry acetone. 
(ii) The rate of the initial pH drop is faster in "wet" than in "dry" methanol.

(iii) The extent of the $\mathrm{pH}$ drop is significantly larger in "wet" than in "dry" methanol.

(iv) The extent of the $\mathrm{pH}$ drop in water is large.

(v) Black precipitation visible to the naked eye only occurs in the experiment with water.

(vi) A red tone in the colour of the solution in experiments using methanol was noted.

To explore these observations, a modelling study was conducted using BatchCAD software. In this software, reaction rate constants are all expressed in $\mathrm{min}^{-1}$ regardless of the difference in kinetic lows. Clearly the units differ to reflect the order of the reaction, and for order $n$ the rate coefficient has units of $\mathrm{mol}^{1-n} \cdot \mathrm{L}^{n-1} \cdot \mathrm{min}^{-1}$.

\section{Modelling Study}

Reactions considered in this modelling study are given in Table 1 while the initial conditions are presented in Table 2. In the experiments, the addition of carbon monoxide was the onset of the reaction while in the modelling study the addition of palladium(II) iodide was taken to initiate the reaction. This was set to occur at the time point when, in the experimental study, purging with carbon monoxide commenced. This change was introduced to simplify modelling of this gas-liquid reaction system. The $\mathrm{pH}$ recorded and expressed as hydrogen ion concentration was considered to be the actual concentration of $\mathrm{HI}$ in the system.

3.1. Water as Solvent. The modelling study of the $\mathrm{PdI}_{2} / \mathrm{KI} /$ $\mathrm{CO}$ reaction system with water as solvent was conducted first using BatchCAD software. This is a gas-liquid reaction system. The solubility of $\mathrm{CO}$ in water is adopted from the literature [15] to be $2.7 \cdot 10^{-2} \mathrm{~g} / \mathrm{dm}^{3}$ at $20^{\circ} \mathrm{C}$, that is, $9.64 \cdot 10^{-4} \mathrm{~mol} / \mathrm{dm}^{3}$. Tonner et al. [14] studied the solubility of carbon monoxide and stated that it takes up to 2 minutes for equilibrium solubility to be achieved. This, together with information on solubility, was included in the modelling study. The reaction system with the $\mathrm{CO}$ concentration of $9.64 \cdot 10^{-4} \mathrm{~mol} / \mathrm{dm}^{3}$ achieved in 2 minutes was created by addition of equations (a) and (b) to the BatchCAD model. The rate constants that fulfil these requirements in $25 \mathrm{~mL}$ of $\mathrm{H}_{2} \mathrm{O}\left(55.55 \mathrm{~mol} / \mathrm{dm}^{3}\right)$ were estimated to be $k_{a}=2.47 \mathrm{~min}^{-1}$ and $k_{b}=2.4 \cdot 10^{-3} \mathrm{~min}^{-1}$.

According to Malashkevich et al. [1] as well as Gorodskii et al. [2, 3], water plays a critical role in the formation of the active catalytic species responsible for the carbonylation process in the PCPOC reaction. In their opinion, the active species is $\operatorname{Pd}(\mathrm{I})$ and the first step towards its formation is reaction $(\mathrm{c})$.

At the same time, Chiusoli et al. [12] and Gabriele et al. [13] acknowledge the role of water in the palladiumcatalysed carbonylation reaction but are of the opinion that the reaction occurs via the formation of an intermediate (reactions $(\mathrm{d})$ and $(\mathrm{e})$ ).

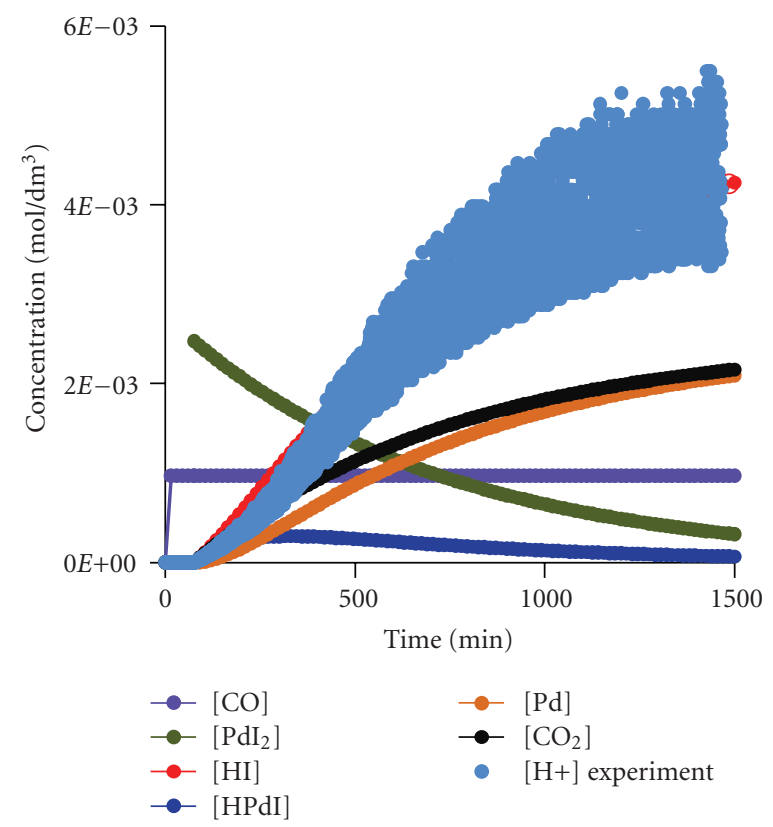

Figure 6: Fitted data using Model 1 against experimental data presented in Figure 2.

Model 1 assumed the direct synthesis of HPdI. Figure 2 shows that at the end of the experiment the $\mathrm{pH}$ was approximately 2.4 indicating an $\left[\mathrm{H}^{+}\right]$concentration of $3.98 \cdot 10^{-3} \mathrm{~mol} / \mathrm{dm}^{3}$. As this value is larger than the initial concentration of $\mathrm{PdI}_{2}$, it suggests that, in addition to the proposed reaction scheme, there is another process responsible for further hydrogen ion formation. The fact that a black precipitate was observed may suggest the formation of $\operatorname{Pd}(0)$. Reaction (f), the decomposition of HPdI, is postulated to account for this. The concentration of water was not included in rate of reaction (c) because this value is large and can be considered constant throughout the course of the reaction.

Rate constants $k_{a}$ and $k_{b}$ were maintained constant $\left(k_{a}=\right.$ $2.47 \mathrm{~min}^{-1}$ and $k_{b}=2.4 \cdot 10^{-3} \mathrm{~min}^{-1}$ ), while the others were estimated to be $k_{c}=1.489 \mathrm{~min}^{-1}$ and $k_{f}=8.413 \cdot 10^{-3} \mathrm{~min}^{-1}$. The fitted data plotted against the experimental data are presented in Figure 6. A good fit was obtained although high dispersion in the experimental data is noted. This appears to be characteristic of the experimental setup which uses a magnetic stirrer as it was not observed when an alternative method of stirring is applied [5-8].

Model 2 considers the synthesis of HPdI via the formation of an intermediate. In rate of reaction $(\mathrm{d})$, the concentration of water was not included because, as in the case of reaction (c), this value is large and can be considered to be constant.

Rate constants $k_{a}$ and $k_{b}$ were maintained constant $\left(k_{a}=\right.$ $2.47 \mathrm{~min}^{-1}$ and $k_{b}=2.4 \cdot 10^{-3} \mathrm{~min}^{-1}$ ), while the others were estimated to be $k_{d}=1.635 \mathrm{~min}^{-1}, k_{e}=1.148 \cdot 10^{-2} \mathrm{~min}^{-1}$, and $k_{f}=7.496 \cdot 10^{-3} \mathrm{~min}^{-1}$. The fitted data plotted against the experimental data are presented in Figure 7. 


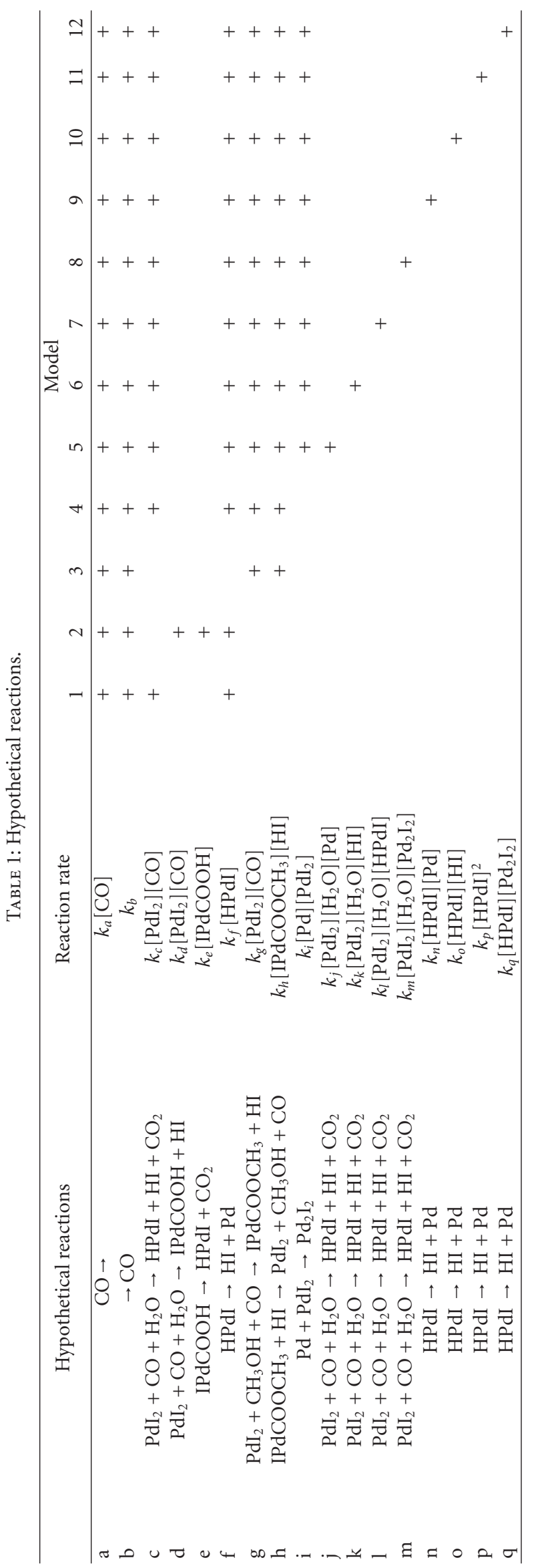


TABLE 2: Initial conditions used in modelling studies.

\begin{tabular}{lccc}
\hline Model & $1-2$ & 3 & $4-12$ \\
\hline$\left[\mathrm{PdI}_{2}\right]\left(\mathrm{mol} / \mathrm{dm}^{3}\right)$ & $2.66 \cdot 10^{-3}$ & $2.66 \cdot 10^{-3}$ & $2.22 \cdot 10^{-3}$ \\
{$[\mathrm{KI}]\left(\mathrm{mol} / \mathrm{dm}^{3}\right)$} & $4.8 \cdot 10^{-1}$ & $4.8 \cdot 10^{-1}$ & $4.8 \cdot 10^{-1}$ \\
{$[\mathrm{CO}]\left(\mathrm{mol} / \mathrm{dm}^{3}\right)$} & $9.64 \cdot 10^{-4}$ & $8.26 \cdot 10^{-3}$ & $8.26 \cdot 10^{-3}$ \\
Solvent $(\mathrm{mL})$ & $25($ Water$)$ & $25($ Dry Methanol) & $25($ Methanol) \\
\hline
\end{tabular}

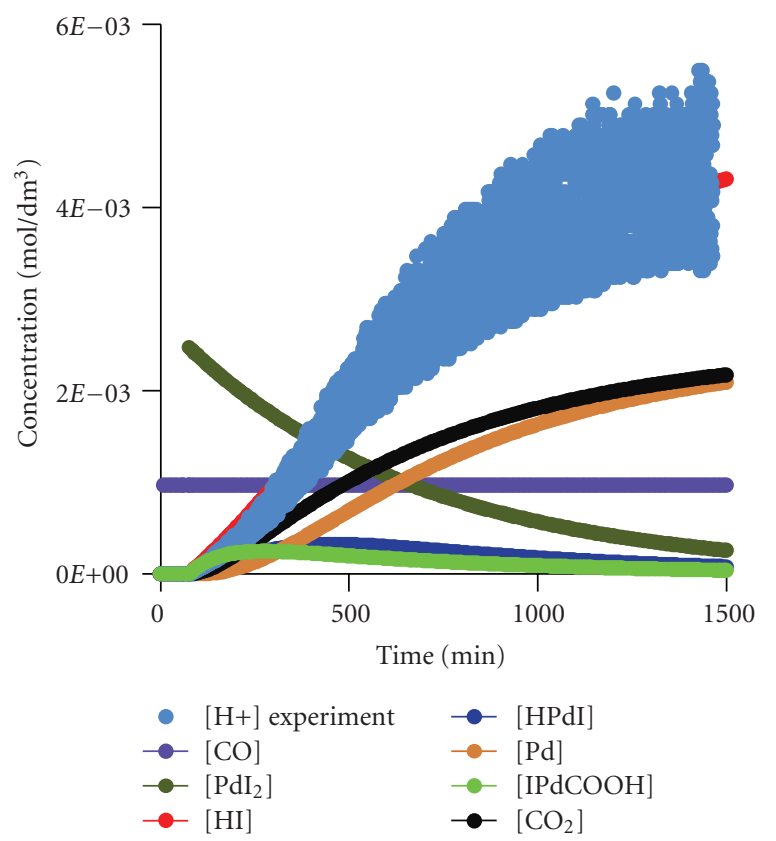

Figure 7: Fitted data using Model 2 against experimental data presented in Figure 2.

From Figures 6 and 7, it can be seen that both models give a similar and reasonably good fit. For this reason in future modelling studies, direct synthesis of HPdI will be assumed rather than its formation via an intermediate (IPdCOOH).

3.2. Dry Methanol as Solvent. The solubility of carbon monoxide in methanol at $20^{\circ} \mathrm{C}$ is estimated to be $8.26 \cdot 10^{-3} \mathrm{~mol} / \mathrm{dm}^{3}$. In BatchCAD software, this was set constant by maintaining rate constant $k_{a}$ at $1 \mathrm{~min}^{-1}$ and $k_{b}$ at $8.26 \cdot 10^{-3} \mathrm{~min}^{-1}$. The equilibrium solubility is now set to be achieved in 15 minutes. This was done to test the influence of a decrease in the carbon monoxide dissolution rate compared to that suggested in the literature (2 minutes).

The $\mathrm{pH}$ fall recorded in the experiment with dry methanol was small (Figure 3) and no precipitate was observed. The adjusted $\mathrm{pH}$ value $\left(\mathrm{pH}_{\mathrm{app}}+2.3\right)$ suggests a small change in hydrogen ion concentration upon $\mathrm{CO}$ addition (from $10^{-10.86}$ to $10^{-7.82}$ ). The reaction system that may explain such behaviour is proposed in Model 3. Reversibility is included in this model to limit the $\mathrm{pH}$ fall. In rate of reaction $(\mathrm{g})$, the concentration of methanol was not included because this value is large and can be considered constant. Rate constants $k_{a}$ and $k_{b}$ were maintained constant ( $k_{a}$ at $1 \mathrm{~min}^{-1}$ and $k_{b}$ at $8.26 \cdot 10^{-3} \mathrm{~min}^{-1}$ ), while the others

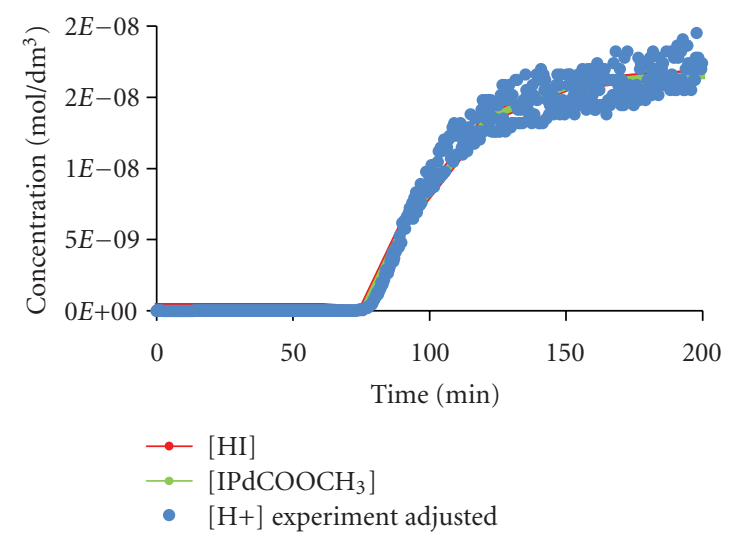

Figure 8: Fitted data using Model 3 against experimental data presented in Figure 3.

were estimated to be $k_{g}=2.013 \cdot 10^{-5} \mathrm{~min}^{-1}$ and $k_{h}=$ $1.535 \cdot 10^{6} \mathrm{~min}^{-1}$.

The fitted data plotted against the experimental data are presented in Figure 8. A good fit was obtained.

3.3. Standard Grade "Wet" Methanol as Solvent. This modelling study was conducted using the adjusted $\mathrm{pH}$ values presented in Figure 4. In the experiment, the solution was filtered to exclude the influence of the rate of $\mathrm{PdI}_{2}$ dissolution. The initial assumption was that the same reactions that were employed in the modelling studies of water as solvent (Model 1) and dry methanol as solvent (Model 3) occur in "wet" methanol. Model 4 was tested. In all "wet" methanol modelling exercises, water was taken into account in rate of reaction (c) (rate: $k_{c}\left[\mathrm{PdI}_{2}\right][\mathrm{CO}]\left[\mathrm{H}_{2} \mathrm{O}\right]$ ) because in this reaction system the concentration of water is relatively low and cannot be considered to be constant. In the standard grade HPLC methanol used, the content of water is declared as less than $0.03 \%\left(1.67 \cdot 10^{-2} \mathrm{~mol} / \mathrm{dm}^{3}\right)$. This is about 7.5 times larger than the initial concentration of $\mathrm{PdI}_{2}$. As the actual initial concentration of water plays a significant role in the proposed model and is not known, several attempts using a range of values were conducted. It was found that an initial concentration of $3.4 \cdot 10^{-4} \mathrm{~mol} / \mathrm{dm}^{3}$ provides the closest fit.

Rate constants $k_{a}$ and $k_{b}$ were maintained constant $\left(k_{a}\right.$ at $1 \mathrm{~min}^{-1}$ and $k_{b}$ at $8.26 \cdot 10^{-3} \mathrm{~min}^{-1}$ ), while the others were estimated to be $k_{c}=1.3 \cdot 10^{3} \mathrm{~min}^{-1}, k_{f}=8.4 \cdot 10^{-3} \mathrm{~min}^{-1}, k_{g}=$ $2 \cdot 10^{-5} \mathrm{~min}^{-1}$, and $k_{h}=1.5 \cdot 10^{6} \mathrm{~min}^{-1}$.

As can be seen from Figure 9, Model 4 does not produce a good fit. It suggests the production of $\operatorname{Pd}(0)$ which disagrees with the lack of the black precipitate observed experimentally. This is accounted for by extending Model 4 with a reaction consuming $\operatorname{Pd}(0)$, that is, reaction (i). In addition, a pronounced disagreement exists between the estimated concentration of HI and the experimentally measured and adjusted hydrogen ion concentration during the initial stages of the reaction. From the experimental data it can be seen that upon CO addition, a slow increase in hydrogen ion concentration commences and then speeds up. This behaviour suggests the presence of catalysis in this system. 
TABLE 3: Rate constants (Models 5-8) estimated using BatchCad kinetic fitting package.

\begin{tabular}{|c|c|c|c|c|c|c|c|c|}
\hline \multirow{2}{*}{ Rate constant $\left(\mathrm{min}^{-1}\right)$} & \multirow{2}{*}{ Model 5} & \multirow{2}{*}{ Model 6} & \multirow{2}{*}{ Model 7} & \multirow{2}{*}{ Model 8} & Model 5 & Model 6 & Model 7 & Model 8 \\
\hline & & & & & \multicolumn{4}{|c|}{ Additional constraint: $[\mathrm{Pd}]=0$} \\
\hline$k_{a}$ & 1 & 1 & 1 & 1 & 1 & 1 & 1 & 1 \\
\hline$k_{b}$ & $8.26 \cdot 10^{-3}$ & $8.26 \cdot 10^{-3}$ & $8.26 \cdot 10^{-3}$ & $8.26 \cdot 10^{-3}$ & $8.26 \cdot 10^{-3}$ & $8.26 \cdot 10^{-3}$ & $8.26 \cdot 10^{-3}$ & $8.26 \cdot 10^{-3}$ \\
\hline$k_{c}$ & $3.88 \cdot 10^{2}$ & $1.69 \cdot 10^{2}$ & $2.59 \cdot 10^{2}$ & $6.74 \cdot 10^{2}$ & $4.15 \cdot 10^{2}$ & $1.69 \cdot 10^{2}$ & $2.59 \cdot 10^{2}$ & $6.74 \cdot 10^{2}$ \\
\hline$k_{f}$ & $3.95 \cdot 10^{-3}$ & $4.16 \cdot 10^{-3}$ & $4.81 \cdot 10^{-3}$ & $9.18 \cdot 10^{-2}$ & $5.14 \cdot 10^{-3}$ & $4.16 \cdot 10^{-3}$ & $4.81 \cdot 10^{-3}$ & $9.18 \cdot 10^{-2}$ \\
\hline$k_{g}$ & $2.38 \cdot 10^{-6}$ & $3.86 \cdot 10^{-6}$ & $5.46 \cdot 10^{-10}$ & $8.38 \cdot 10^{-16}$ & $3.53 \cdot 10^{-7}$ & $3.86 \cdot 10^{-6}$ & $5.46 \cdot 10^{-10}$ & $8.40 \cdot 10^{-16}$ \\
\hline$k_{h}$ & $5.69 \cdot 10^{-3}$ & $8.04 \cdot 10^{-3}$ & $6.01 \cdot 10^{-3}$ & $1.53 \cdot 10^{-5}$ & $3.21 \cdot 10^{-3}$ & $8.04 \cdot 10^{-3}$ & $6.01 \cdot 10^{-3}$ & $1.53 \cdot 10^{-5}$ \\
\hline$k_{i}$ & $1.52 \cdot 10^{-6}$ & $7.63 \cdot 10^{-7}$ & $2.22 \cdot 10^{-6}$ & $2.00 \cdot 10^{1}$ & $1.00 \cdot 10^{2}$ & $1.00 \cdot 10^{2}$ & $1.00 \cdot 10^{2}$ & $3.97 \cdot 10^{1}$ \\
\hline$k_{j}$ & $2.66 \cdot 10^{7}$ & & & & $5.18 \cdot 10^{7}$ & & & \\
\hline$k_{k}$ & & $1.39 \cdot 10^{6}$ & & & & $1.39 \cdot 10^{6}$ & & \\
\hline$k_{l}$ & & & $1.21 \cdot 10^{6}$ & & & & $1.21 \cdot 10^{6}$ & \\
\hline$k_{m}$ & & & & 2.63 & & & & 2.63 \\
\hline
\end{tabular}

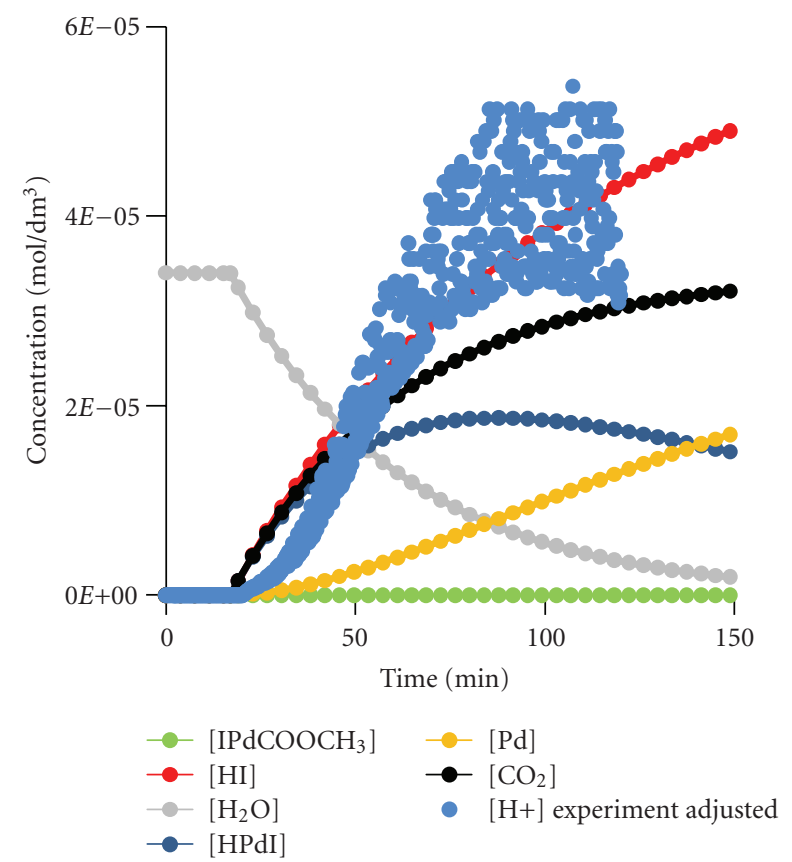

Figure 9: Fitted data using Model 4 against experimental data presented in Figure 4.

Two reactions are considered responsible for the production of hydrogen ions (reactions (c) and (f)) so the influence of catalysis in both cases was investigated.

The species tested to act as catalyst of reaction (c) are $\operatorname{Pd}(0)$ (Model 5), HI (Model 6), HPdI (Model 7), and $\mathrm{Pd}_{2} \mathrm{I}_{2}$ (Model 8). The same models are then used with the constraint that the $\operatorname{Pd}(0)$ concentration is zero. Results are presented in Figures 10 and 11. Estimated rate constants are presented in Table 3. It can be seen that good fits were obtained using Models 5-7, while Model 8 was slightly less succesful.

The same species are now tested to act as catalyst of reaction (f) (Pd(0) (Model 9), HI (Model 10), HPdI (Model 11), and $\mathrm{Pd}_{2} \mathrm{I}_{2}$ (Model 12). The same models are then used with the constraint that the $\operatorname{Pd}(0)$ concentration is zero. In all cases, the fit achieved was poor and similar to the one achieved using Model 4 (Figure 9). A pronounced disagreement was noted between the estimated concentration of $\mathrm{HI}$ and the experimentally measured and adjusted hydrogen ion concentration during the initial stages of the reaction.

\section{Discussion and Conclusions}

The work presented in this paper studies the interaction between methanol, palladium(II) iodide, potassium iodide, and carbon monoxide. Understanding this subsystem is an important step towards revealing the reaction network responsible for the oscillatory behaviour seen in the PCPOC reaction.

It was demonstrated previously that the occurrence of the oscillatory mode of the PCPOC reaction depends on the granularity of palladium(II) iodide added to the system [6]. At the same time, it was experimentally shown that stirrer agitation speed influences the appearance of oscillations [5]. While the influence of granularity and hence catalytic surface area may indicate solid-liquid catalysis, the dependence on agitation speed may suggest gas-liquid mass transfer limitations. However, both of these observations may also suggest the slow rate of palladium(II) iodide solubility. This paper confirms that the solubility of palladium(II) iodide in methanol is low and for this reason potassium iodide is added [5-8]. Although in the presence of potassium iodide $\mathrm{PdI}_{2}$ solubility in methanol increases, the rate of solubility remains slow. To overcome this issue in the experiment used in the kinetic study of the "wet" methanol as solvent (Figure 4$)$, the catalytic mixture $\left(\mathrm{PdI}_{2}\right.$ and $\mathrm{KI}$ in $\left.\mathrm{CH}_{3} \mathrm{OH}\right)$ was filtered. The amount of palladium(II) iodide left on the filter was measured and the actual initial concentration of $\mathrm{PdI}_{2}$ remaining in methanol was calculated.

The importance of water in the palladium(II) iodide reaction with carbon monoxide was postulated previously $[1-3,12,16]$. However, actual validation with experimentally obtained data was lacking. In this paper, it was experimentally demonstrated that water has a significant role in this reaction. One observation from these experiments is that 


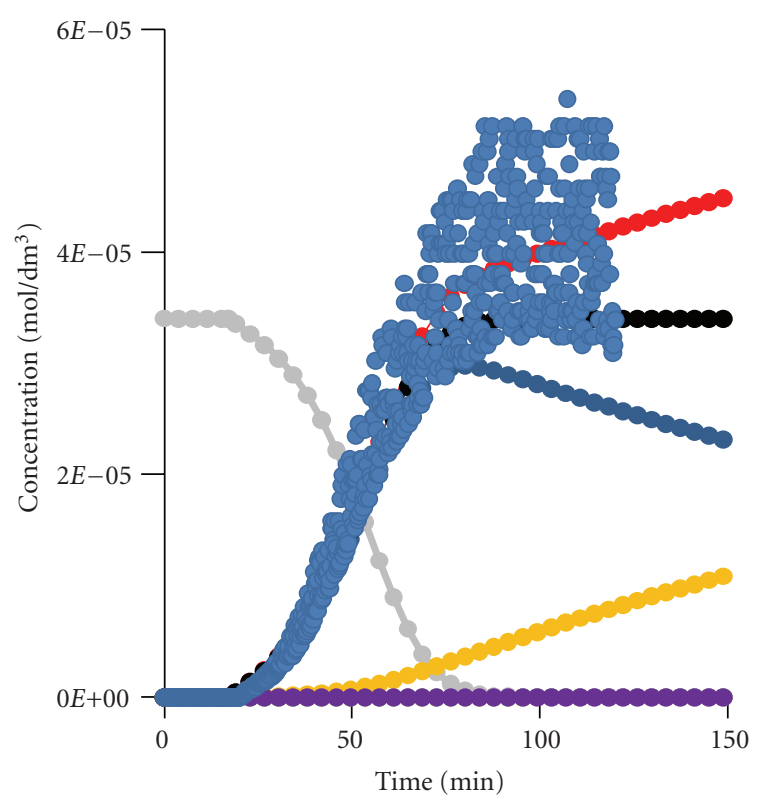

(a) Model 5

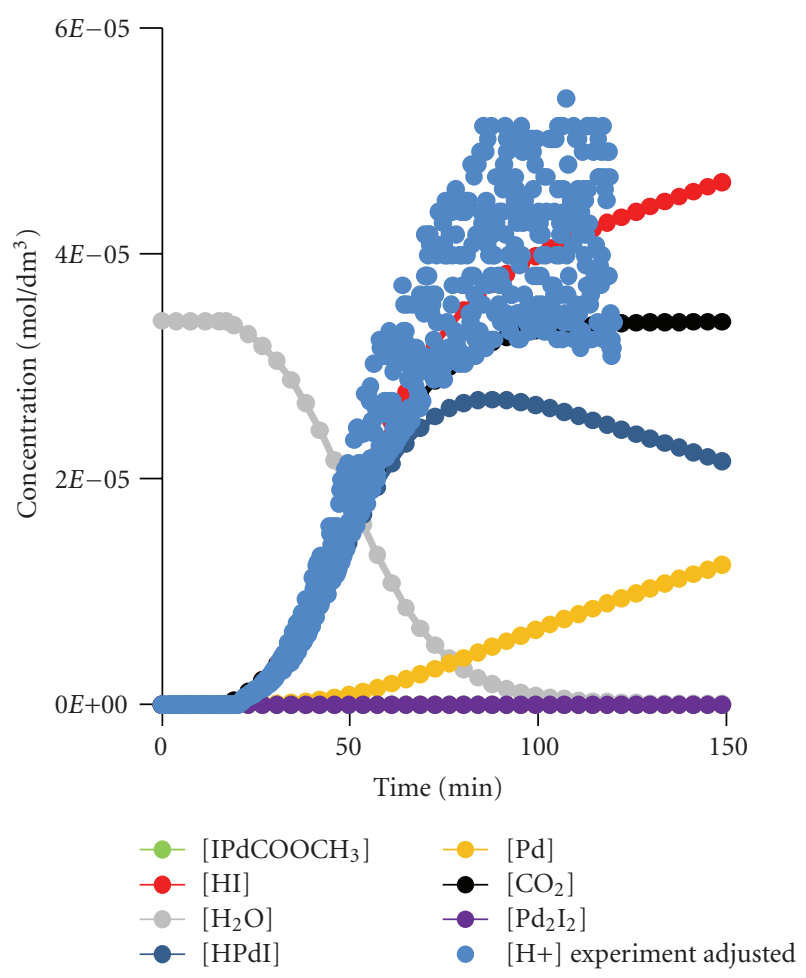

(c) Model 7

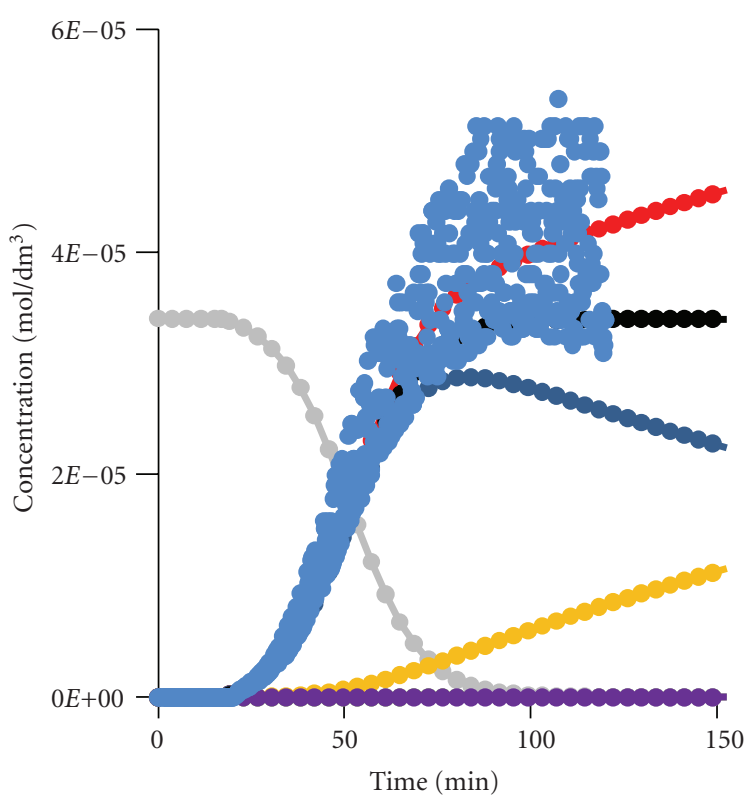

(b) Model 6

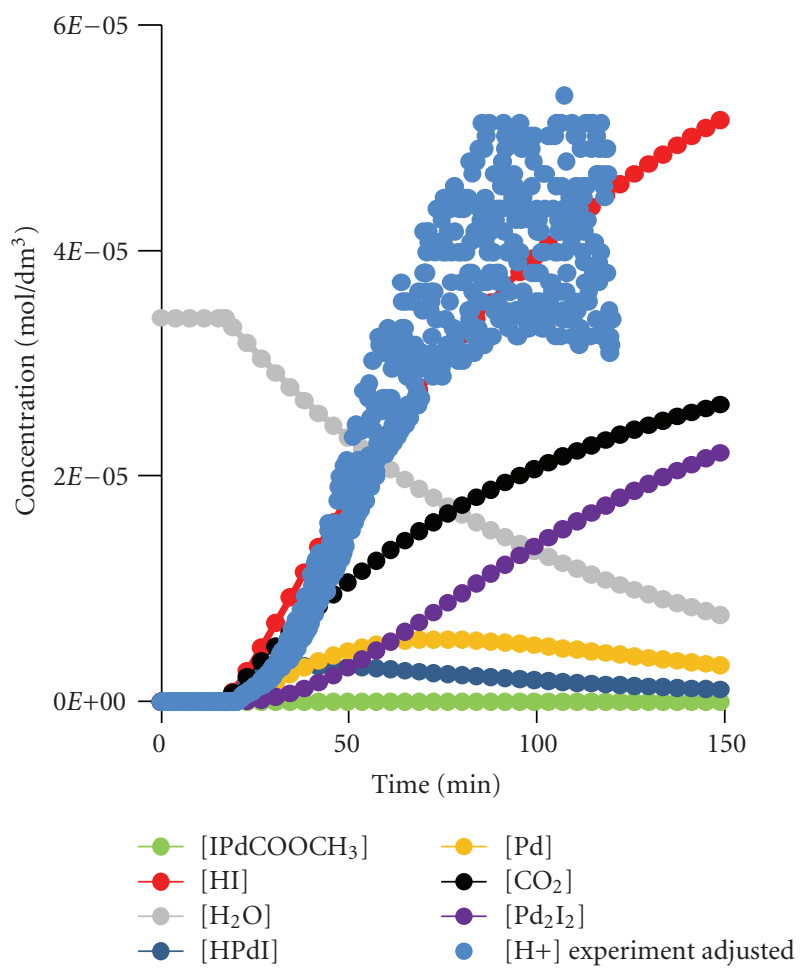

(d) Model 8

FIGURE 10: Fitted data using models 5-8 against experimental data presented in Figure 4.

the $\mathrm{pH}$ drop upon carbon monoxide addition to the $\mathrm{PdI}_{2} / \mathrm{KI}$ mixture occurs only in the systems with a component that may act as a proton donor.

In the system with water as solvent, a significant $\mathrm{pH}_{\text {app }}$ drop was recorded (Figure 2). A reaction that produces HPdI and $\mathrm{HI}$ is considered to initiate the process (reaction (c) or reaction system (d) and (e)) as suggested by a number of researchers $[1-3,12,16]$. Although the actual initial concentration of palladium(II) iodide in water was not known, it become apparent that even if all of the palladium(II) iodide added reacted to form HPdI and HI, the amount of HI produced would be less than that experimentally recorded. During the addition of carbon monoxide in this experiment, the colour of the solution changed from brown 


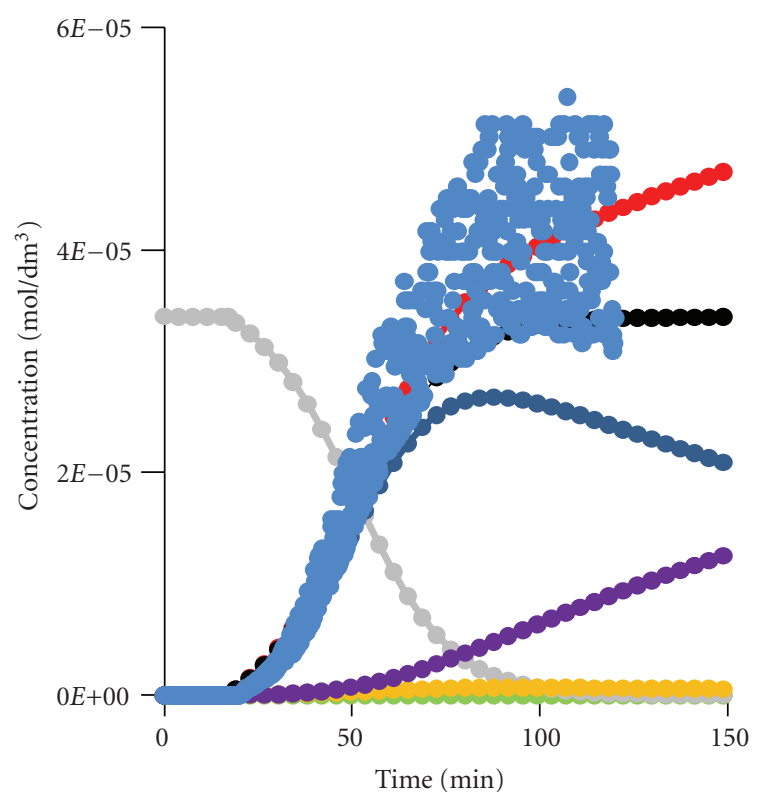

(a) Model 5

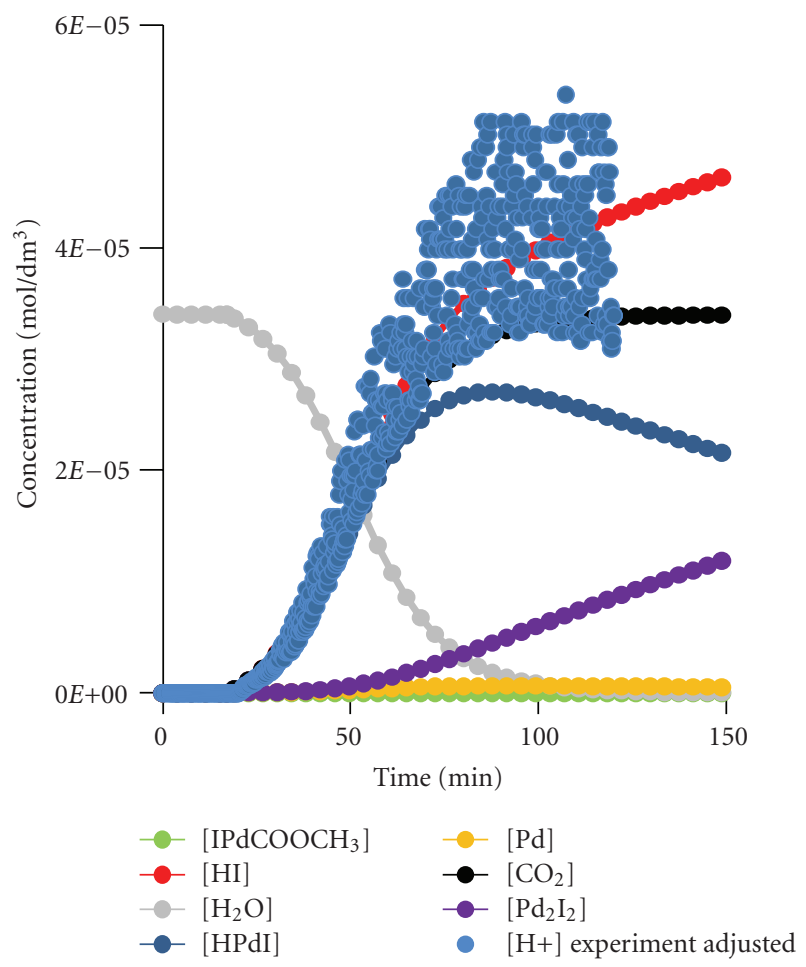

(c) Model 7

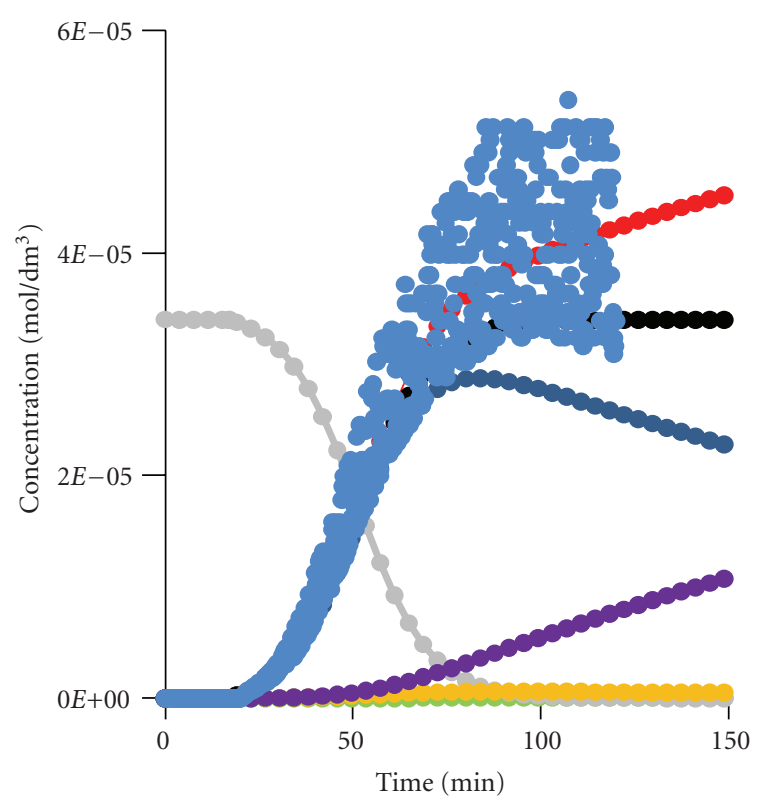

(b) Model 6

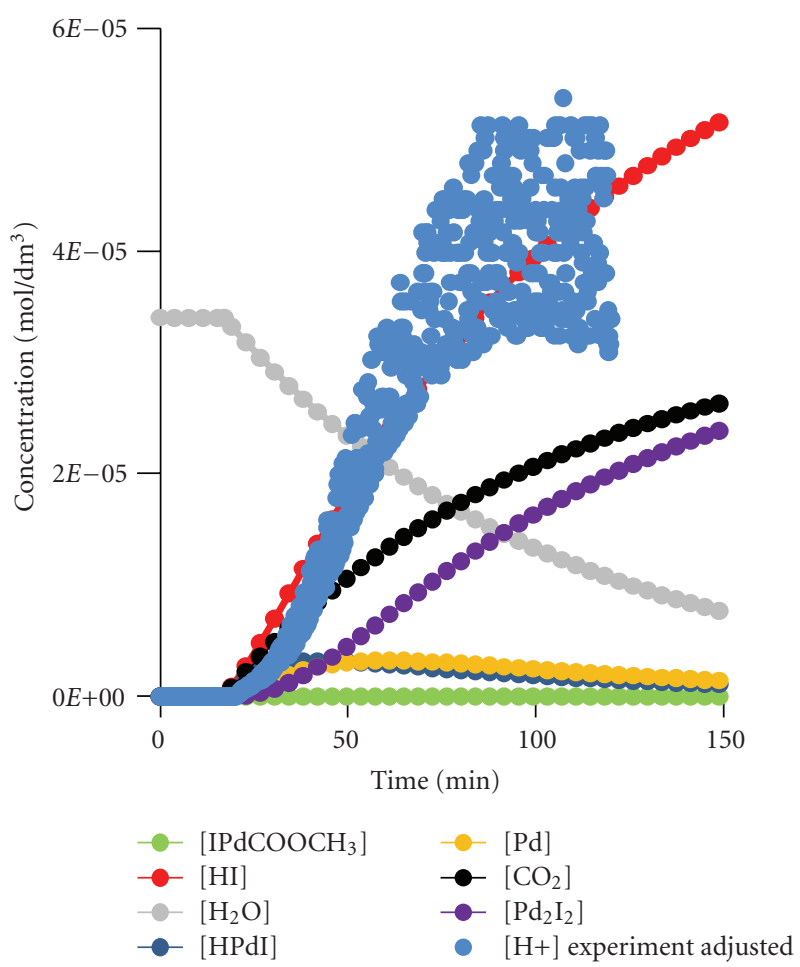

(d) Model 8

FIGURE 11: Fitted data using models 5-8 and $[\mathrm{Pd}]=0$ against experimental data presented in Figure 4.

to colourless and a black precipitate occurred. A reaction that may explain both the formation of a black precipitate and the increase in hydrogen ion concentration is HPdI decomposition to $\mathrm{HI}$ and $\operatorname{Pd}(0)$ (reaction (f)). When modelling this reaction system, two cases were considered: HPdI formation via a one-step reaction and HPdI formation via a two-step reaction. An equally good fit was obtained in both cases, and it was not possible to differentiate between them.
Although the catalytic mixtures of $\mathrm{PdI}_{2} / \mathrm{KI}$ in water (Figure 2) and dry methanol (Figure 3) were not filtered prior to carbon monoxide addition, experimental data were used to qualitatively study and also postulate chemical reactions responsible for the observed $\mathrm{pH}$ behaviour. In the system with dry methanol as solvent (Figure 3), a very small change in hydrogen ion concentration was recorded upon carbon monoxide addition. This was accounted for in Model 3 by including a reversible reaction in which 
$\mathrm{IPdCOOCH}_{3}$ and HI are formed. Analysis to confirm the existence of $\mathrm{IPdCOOCH}_{3}$ was not conducted. Although it is likely that this product further decomposes forming HPdI and/or $\mathrm{Pd}_{2} \mathrm{I}_{2}$, these reactions were not considered. As Model 3 already fits the experimental data, more experimentally obtained variables would be needed to differentiate between any additional reactions. This will be done, once phenylacetylene is included in this reaction system and reactant/product composition becomes available.

The modelling study of $\mathrm{PdI}_{2} / \mathrm{KI}$ carbonylation in "wet" methanol using experimentally obtained data (Figure 4) revealed at least one more reaction taking place in this system. Throughout the experiment, a rich brown-burgundy colour was observed but the black precipitate was absent suggesting a chemical reaction that consumes $\operatorname{Pd}(0)$. This may be accounted for by reaction (i) that is, the formation of $\mathrm{Pd}_{2} \mathrm{I}_{2}$. At the same time, a catalytic effect on the formation of hydrogen ions is observed. It was noted that upon $\mathrm{CO}$ addition, a slow increase in hydrogen ion concentration commences and then speeds up (Figures 1 and 4). For this reason, the catalytic effect on reactions responsible for hydrogen ion formation is postulated and tested. First reaction (c) is tested. Various species were postulated to act as catalyst (Pd-Model 5, HI-Model 6, HPdI-Model 7, and $\mathrm{Pd}_{2} \mathrm{I}_{2}-$ Model 8). The case where the adjusted hydrogen ion concentration is used as the only experimental variable is presented in Figure 10 with estimated rate constants given in Table 3. As can be seen, an equally good agreement is achieved when either Pd, HI, or HPdI is assumed to be catalysts of reaction (c). A slightly poorer fit was obtained when $\mathrm{Pd}_{2} \mathrm{I}_{2}$ was postulated to act as the catalytic species. The case with two variables (adjusted hydrogen ion concentration and $\operatorname{Pd}(0)$ concentration maintained at zero) was then considered. Again Models 5-8 were used and results are presented in Figure 11 with estimated rate constants given in Table 3. As in the previous case, equally good agreement is achieved when either Pd, HI, or HPdI is assumed to be catalysts of reaction (c), while a slightly poorer fit was obtained with $\mathrm{Pd}_{2} \mathrm{I}_{2}$. Finally models that included a catalytic effect on reaction (f) (Models 9-12) were studied and the resulting fit was unsatisfactory. It is therefore concluded that catalysis of reaction (c) may be considered responsible for the experimentally observed behaviour. At the same time, it was not possible to differentiate which product $\mathrm{Pd}, \mathrm{HI}$, HPdI, or $\mathrm{Pd}_{2} \mathrm{I}_{2}$ is behind this phenomenon. An important finding from the modelling study of "wet" methanol is the importance of the concentration of water in this reaction system which is related not only to the occurrence of a $\mathrm{pH}$ drop upon $\mathrm{CO}$ addition but also to the rate and extent of this drop.

It should be noted that the models used in the parameter estimation study consist of up to eight reactions; however, only one variable $\left(\mathrm{pH}_{\mathrm{app}}\right)$ is experimentally measured. For this reason, the estimated rate constants should be taken as an indication of the model plausibility rather than as exact values. Further studies in the presence of additional variables from the PCPOC reaction system such as phenylacetylene and oxygen will be conducted. At the same time, as the actual concentration of carbon monoxide in the reaction system is not known, gas-liquid mass transfer phenomena need to be explored further. This will be addressed in our future studies.

\section{Acknowledgments}

The authors wish to acknowledge the UK Engineering and Physical Sciences Research Council (EPSRC) Grant no. EP/ H003908/1 for funding this research. Mrs Julie Parker would like to acknowledge Professor Allen Wright for funding her Ph.D. studies.

\section{References}

[1] A. V. Malashkevich, L. G. Bruk, and O. N. Temkin, "New oscillating reaction in catalysis by metal complexes: a mechanism of alkyne oxidative carbonylation," Journal of Physical Chemistry A, vol. 101, no. 51, pp. 9825-9827, 1997.

[2] S. N. Gorodskii, A. N. Zakharov, A. V. Kulik, L. G. Bruk, and O. N. Temkin, "Oxidative carbonylation of alkynes in an oscillation mode: I. Concentration limits for oscillations in the course of phenylacetylene carbonylation and possible mechanisms of the process," Kinetics and Catalysis, vol. 42, no. 2, pp. 251-263, 2001.

[3] S. N. Gorodskii, E. S. Kalenova, L. G. Bruk, and O. N. Temkin, "Oxidative carbonylation of alkynes in self-oscillating mode. Effect of the nature of substrates on the dynamic behavior of reaction system," Russian Chemical Bulletin, vol. 52, no. 7, pp. 1534-1543, 2003.

[4] O. N. Temkin and L. G. Bruk, "Palladium(II, I, 0) complexes in catalytic reactions of oxidative carbonylation," Kinetics and Catalysis, vol. 44, no. 5, pp. 601-617, 2003.

[5] K. Novakovic, C. Grosjean, S. K. Scott, A. Whiting, M. J. Willis, and A. R. Wright, "Achieving $\mathrm{pH}$ and $\mathrm{Qr}$ oscillations in a palladium-catalysed phenylacetylene oxidative carbonylation reaction using an automated reactor system," Chemical Physics Letters, vol. 435, no. 1-3, pp. 142-147, 2007.

[6] K. Novakovic, C. Grosjean, S. K. Scott, A. Whiting, M. J. Willis, and A. R. Wright, "The influence of oscillations on product selectivity during the palladium-catalysed phenylacetylene oxidative carbonylation reaction," Physical Chemistry Chemical Physics, vol. 10, no. 5, pp. 749-753, 2008.

[7] C. Grosjean, K. Novakovic, S. K. Scott, A. Whiting, M. J. Willis, and A. R. Wright, "Product identification and distribution from the oscillatory versus non-oscillatory palladium(II) iodide-catalysed oxidative carbonylation of phenylacetylene," Journal of Molecular Catalysis A, vol. 284, no. 1-2, pp. 33-39, 2008.

[8] K. Novakovic, A. Mukherjee, M. Willis, A. Wright, and S. Scott, "The influence of reaction temperature on the oscillatory behaviour in the palladium-catalysed phenylacetylene oxidative carbonylation reaction," Physical Chemistry Chemical Physics, vol. 11, no. 40, pp. 9044-9049, 2009.

[9] L. Brannon-Peppas, "Polymers in controlled drug delivery," Medical Plastics and Biomaterials, vol. 4, pp. 34-44, 1997.

[10] M. Roses, "Determination of the $\mathrm{pH}$ of binary mobile phases for reversed-phase liquid chromatography," Journal of Chromatography A, vol. 1037, no. 1-2, pp. 283-298, 2004.

[11] S. P. Porras and E. Kenndler, "Capillary zone electrophoresis in non-aqueous solutions: $\mathrm{PH}$ of the background electrolyte," Journal of Chromatography A, vol. 1037, no. 1-2, pp. 455-465, 2004. 
[12] G. P. Chiusoli, M. Costa, L. Cucchia, B. Gabriele, G. Salerno, and L. Veltri, "Carbon dioxide effect on palladium-catalyzed sequential reactions with carbon monoxide, acetylenic compounds and water," Journal of Molecular Catalysis A, vol. 204205, pp. 133-142, 2003.

[13] B. Gabriele, G. Salerno, M. Costa, and G. P. Chiusoli, "Combined oxidative and reductive carbonylation of terminal alkynes with palladium iodide-thiourea catalysts," Journal of Organometallic Chemistry, vol. 503, no. 1, pp. 21-28, 1995.

[14] S. P. Tonner, M. S. Wainwright, D. L. Trimm, and N. W. Cant, "Solubility of carbon monoxide in alcohols," Journal of Chemical and Engineering Data, vol. 28, no. 1, pp. 59-61, 1983.

[15] http://en.wikipedia.org/wiki/Carbon_monoxide.

[16] B. Gabriele, L. Veltri, G. Salerno, M. Costa, and G. P. Chiusoli, "Synthesis of maleic anhydrides and maleic acids by Pd-catalyzed oxidative dicarbonylation of alk-1-ynes," The European Journal of Organic Chemistry, no. 9, pp. 1722-1728, 2003. 

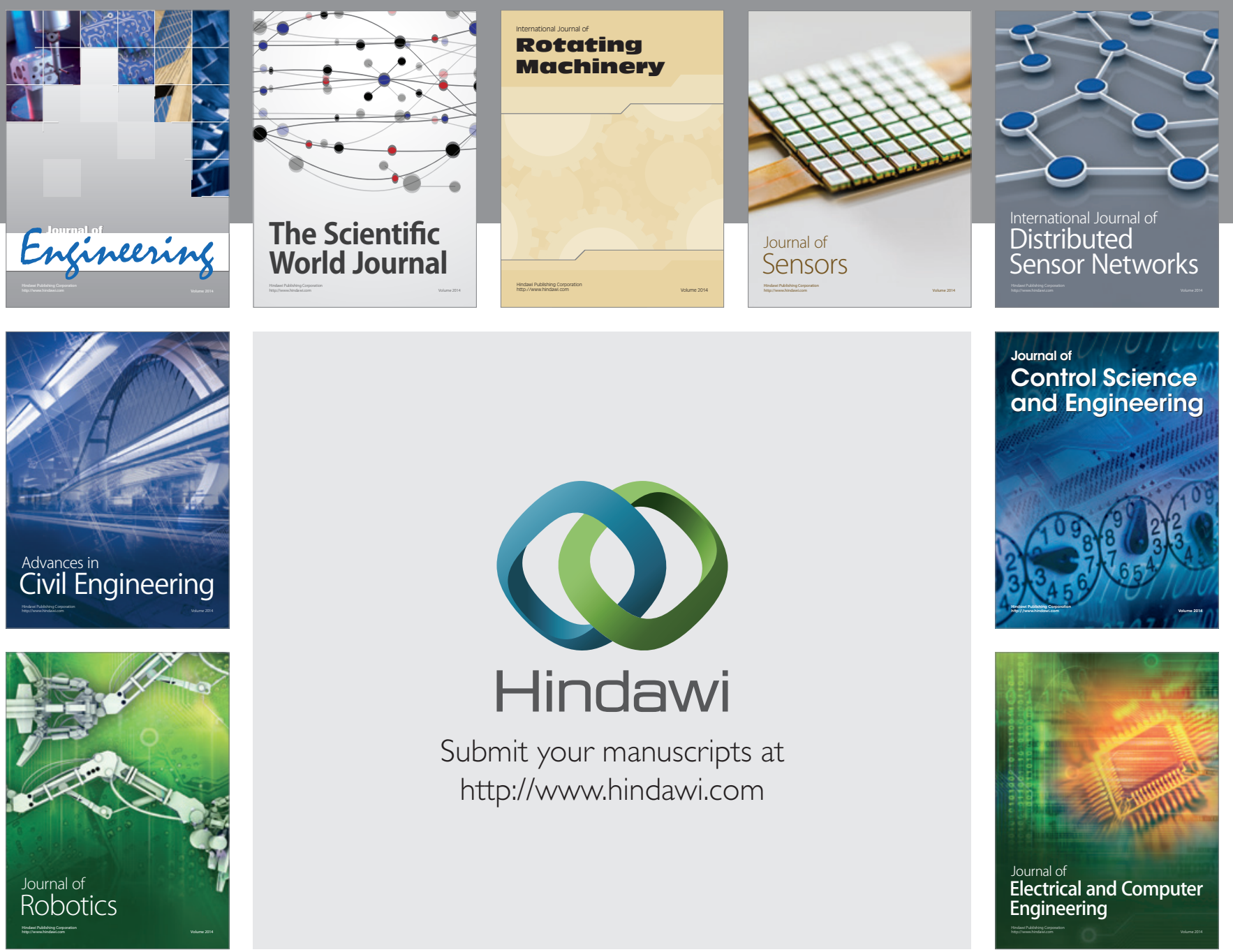

Submit your manuscripts at

http://www.hindawi.com
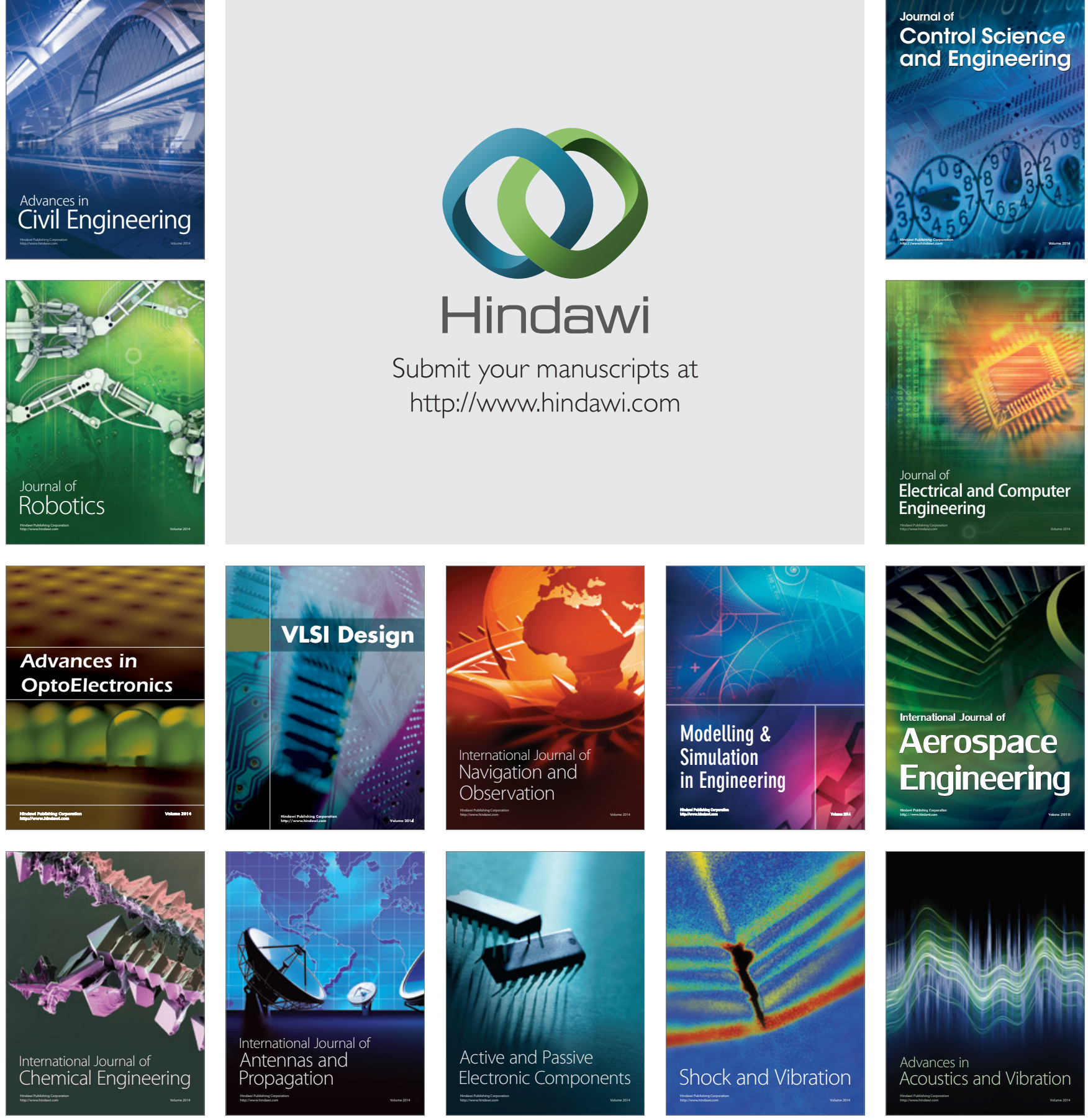